\title{
Aspirin for Prevention of Preeclampsia
}

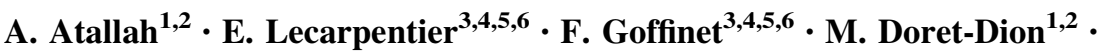 \\ P. Gaucherand ${ }^{1,2} \cdot$ V. Tsatsaris ${ }^{3,4,5,6}$
}

Published online: 16 October 2017

(C) The Author(s) 2017. This article is an open access publication

\begin{abstract}
Aspirin is currently the most widely prescribed treatment in the prevention of cardiovascular complications. The indications for the use of aspirin during pregnancy are, however, the subject of much controversy. Since the first evidence of the obstetric efficacy of aspirin in 1985, numerous studies have tried to determine the effect of lowdose aspirin on the incidence of preeclampsia, with very controversial results. Large meta-analyses including individual patient data have demonstrated that aspirin is effective in preventing preeclampsia in high-risk patients, mainly those with a history of preeclampsia. However, guidelines regarding the usage of aspirin to prevent preeclampsia differ considerably from one country to another. Screening modalities, target population, and aspirin dosage are still a matter of debate. In this review, we report the pharmacodynamics of aspirin, its main effects according to dosage and gestational age, and the evidence-based indications for primary and secondary prevention of preeclampsia.
\end{abstract}

V. Tsatsaris

vassilis.tsatsaris@aphp.fr

1 Hospices Civils de Lyon, Department of Obstetrics and Gynecology, Femme Mère Enfant Hospital, University Hospital Center, 59 boulevard Pinel, 69500 Bron, France

2 Claude-Bernard University Lyon1, Lyon, France

3 Assistance Publique-Hôpital de Paris, Department of Obstetrics and Gynecology, Port-Royal Maternity, University Hospital Center Cochin Broca Hôtel Dieu, Groupe Hospitalier Universitaire Ouest, 53, Avenue de l'Observatoire, 75014 Paris, France

4 PRES Sorbonne Paris Cité, Université Paris Descartes, Paris, France

5 PremUP Foundation, Paris, France

6 DHU Risques et Grossesse, Paris, France

\section{Key points}

Indications for aspirin during pregnancy are a great matter of debate and there is a recent trend to a wide prescription of aspirin in pregnancy.

Aspirin is effective in secondary prevention of preeclampsia mainly in patients with a history of preeclampsia.

The efficacy of aspirin in patients at high risk of preeclampsia, but without previous hypertensive disorder of pregnancy, is controversial.

Aspirin efficacy for the prevention of preeclampsia is dose-dependent, but the optimum dosage, $75 \mathrm{mg} /$ day to $150 \mathrm{mg} / \mathrm{day}$, needs to be determined. Safety data at $150 \mathrm{mg} /$ day are still limited.

Aspirin, in primary prevention of preeclampsia, given to high-risk patients identified in the first trimester by screening tests, seems to reduce the occurrence of early-onset preeclampsia. However, there are insufficient data for the implementation of such screening procedures in practice.

\section{Introduction}

Aspirin is currently the most widely prescribed treatment in the prevention of cardiovascular complications [1]. At low doses, aspirin is also widely used to prevent pregnancyrelated vascular disorders, such as preeclampsia and intrauterine growth restriction, and maternal disorders like antiphospholipid syndrome. The indications for the use of 
aspirin during pregnancy are, however, the subject of much controversy. Proof of its efficacy is not established in a good number of these indications, yet it is being prescribed in an ever-increasing proportion of pregnant women [2].

Preeclampsia is a multisystem disorder of pregnancy that is usually defined as hypertension and proteinuria diagnosed after 20 weeks of gestation. Hypertension in pregnancy is defined as a systolic blood pressure of $140 \mathrm{mmHg}$ or more and a diastolic blood pressure of $90 \mathrm{mmHg}$ or more in two separate measurements at least 4-6 h apart. However, correct measurement of blood pressure is indispensable in diagnosing hypertension [3]. There is currently no official role of ambulatory blood pressure measurement in the diagnosis of hypertensive pregnancy disorders [4]. Preeclampsia may be difficult to diagnose, especially in patients with chronic diseases associated with hypertension or proteinuria. Preeclampsia can lead to liver and kidney failure, seizures (eclampsia), and abnormalities of the clotting system [5]. Since 2013, the traditional definition has been reviewed and, in the absence of proteinuria, it is specified that preeclampsia may be diagnosed as hypertension in association with recent onset of thrombocytopenia, impaired liver function, renal insufficiency, pulmonary edema, or new-onset cerebral or visual disturbances [6]. This wide definition has introduced more inconsistency in the way preeclampsia is diagnosed in clinical practice. Preeclampsia occurs in 1-8\% of pregnant women [5], a range of prevalence related to variability in the risk factors of pregnant women from one country to another. In Europe, preeclampsia affects $1 \%$ of the general population, including $1.5 \%$ of nulliparas [7]. Although its prevalence is low, preeclampsia causes substantial maternal and perinatal morbidity, is the second cause of maternal mortality worldwide [8], and is one of the five leading causes of maternal mortality in the developed world [9]. Apart from delivery, there is no effective treatment for preeclampsia, making primary and secondary prevention of preeclampsia a major public health issue.

For over 30 years, the role of aspirin in the primary or secondary prevention of preeclampsia has been the subject of numerous studies and great controversy. The indications for aspirin, its dosage, and gestational age at the start of aspirin treatment are still debated. Our aim here was to provide an update on the modes of action of aspirin and on its indications in the prevention of preeclampsia.

\section{Pharmacology of Aspirin}

\subsection{History}

Around $460 \mathrm{BC}$, Hippocrates recommended herbal tea made from the leaves of the white willow (Salix alba) to alleviate pain and fever. Much later, in 1829, French pharmacist Pierre Joseph Leroux obtained crystals of salicin after boiling the powdered bark of white willow. In 1842, Raffaele Piria performed the first synthesis of salicylic acid from salicin, a little before Hermann Kolbe prepared salicylic acid from sodium phenate and carbon dioxide. In 1953, Charles Gerhardt was the first to isolate acetylsalicylic acid, and, in 1971, John Vane discovered its mechanism of action, work for which he won the 1982 Nobel Prize in Physiology of Medicine [10, 11]. Later research showed that aspirin works by inhibiting cyclooxygenase, the enzyme responsible for converting arachidonic acid into prostaglandins [12].

\subsection{Synthesis and Principal Effects of Prostaglandins}

Prostaglandins are lipid-soluble molecules synthesized from arachidonic acid, a 20-carbon chain fatty acid, by the action of cyclooxygenase (COX) [13]. The first step involves the release of arachidonic acid from cellular stocks. Arachidonic acid is not free, but is acetylated to the phospholipid membrane. The best-known release pathway is that of phospholipase A2 in its cytoplasmic or calciumdependent form. Another signaling pathway involving phospholipase $\mathrm{C}$ cleaves inositol triphosphate, thus releasing diacylglycerol, which is hydrolyzed into monoacylglycerol before being released as arachidonic acid and glycerol [14].

Once free inside the cell, arachidonic acid is metabolized into eicosanoids. First, COX converts arachidonic acid into prostaglandin $\mathrm{G} 2$ via an oxygenase reaction, and then into prostaglandin $\mathrm{H} 2$ (PGH2) via a peroxidase reaction. $\mathrm{PGH} 2$ is subject to the effect of enzymes (prostaglandin synthases) specific to the synthesis of various prostaglandins. Thus, prostacyclin synthases are key to the synthesis of prostacyclins downstream of COX (Fig. 1) [14].

The expression of these prostacyclin synthases determines the release of eicosanoids in certain types of cells. Although they express the same isoforms of COX as endothelial cells, platelets differ in function. Prostacyclin synthases are strongly expressed in endothelial cells, but thromboxane synthase is expressed little, or not at all. In contrast, thromboxane synthase is highly expressed in platelets, where the level of prostacyclin synthases is negligible. So, despite high expression of COX in these 2 cell types, the production of prostaglandins predominates, thus enabling diametrically opposed biological functions [13, 15].

The platelet-endothelium interaction has often been studied in terms of the fine regulation of the effects of prostaglandins. Thus, the biological effect is determined by the equilibrium between endothelial prostacyclin and platelet thromboxane [15]. 
Fig. 1 Biosynthesis of eicosanoids. $\mathrm{PGH} 2$ prostaglandin $\mathrm{H} 2, P G H E 2$ prostaglandin E2, $P G H D 2$ prostaglandin D2, $P G F 2 \alpha$ prostaglandin F2 alpha, $P G I 2$ prostaglandin $\mathrm{I} 2, T X A 2$ thromboxane A2

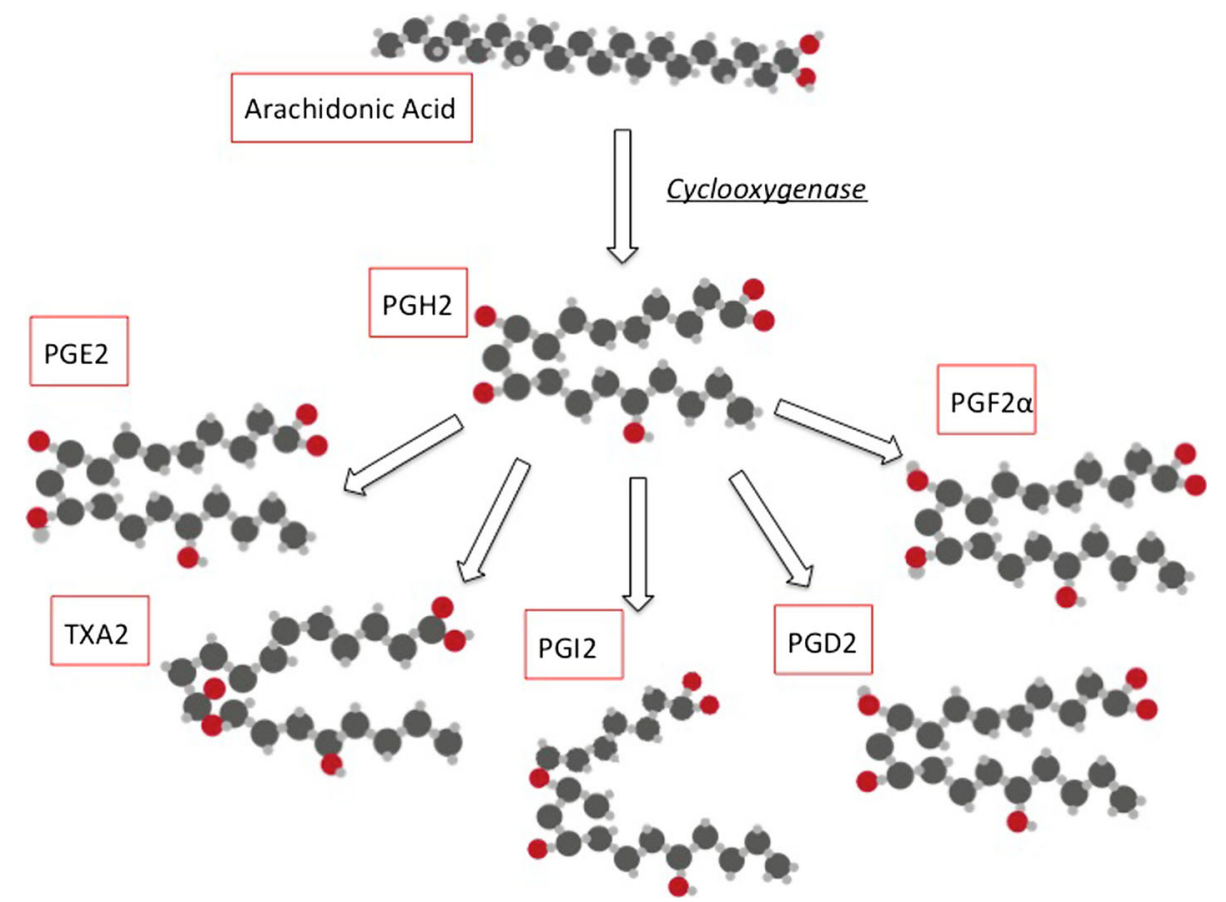

Thromboxane A2 (TXA2) is produced by platelets, and also the placenta [16], and is responsible for vasoconstriction, induction of vascular remodeling, and increasing platelet aggregation and adhesion. Prostacyclins are vasodilatory mediators and inhibit vascular remodeling, platelet aggregation, and platelet adhesion [13].

\subsection{Pharmacokinetics of Aspirin}

In homeostasis, arachidonic acid is converted into PGH2 by constitutive COX 1, and by inducible COX 2 in cases of inflammatory reaction, hypoxia, or oxidative stress. This induction is mediated by numerous cytokines and pro-inflammatory factors [17, 18]. The synthesis of prostaglandins is dependent on $\mathrm{PGH} 2$, a common precursor, which enables the endothelial production of prostaglandin I2 (PGI2) and platelet production of TXA2 $[19,20]$.

Aspirin is quickly absorbed in the stomach and upper digestive tract. The fraction absorbed depends on various factors, such as the dissolution of the tablets, the dosage form, and gastrointestinal $\mathrm{pH}$ [21]. After oral administration, the plasma peak is reached in 30 min [21]. Aspirin, which is a weak acid ( $\mathrm{pH}$ 3.5), is hydrolyzed in the intestinal circulation to salicylic acid [21], which is rapidly conjugated (via catalysis of acyl-CoA $N$-acyltransferase) to form the principal metabolite, salicyluric acid, which is excreted in urine (Fig. 2) [22]. A single oral dose of 5-100 mg of aspirin, dose-dependently inhibits the activity of platelet COX [23]. The half-life of aspirin ranges from 1 to $38 \mathrm{~h}$ in animals, but is close to $20 \mathrm{~min}(13-31 \mathrm{~min})$ in human subjects. The slow elimination of salicylates is linked to the high plasma level of protein transporters [21].

\subsection{Mode of Action of Aspirin}

Acetylsalicylic acid (aspirin) is transformed into salicylic acid, which induces the acetylation of a serine at the heart of $\mathrm{COX}$ and binds to its catalytic site, thereby preventing the binding of arachidonic acid (Fig. 3). This blocking of the catalytic site of COX is dose-dependent, stable, covalent, and irreversible. It is mainly responsible for the inhibition of COX-1, a constitutive enzyme, while there is less inhibition of COX-2, an inducible enzyme. The duration of action of aspirin depends on the capacity of the cell to resynthesize COX [24].

The half-life of acetylsalicylic acid being very short, the neo-synthesis of COX allows the resumption of prostaglandin production some hours after a dose of aspirin. Thus, the endothelium recovers its physiological state by de novo synthesis of COX, which ensures basal secretion of PGI2 [25]. The platelet, where TXA2 is synthesized, is anuclear and cannot compensate for this acetylation state. The inhibition of COX will, therefore, last for the whole life of the platelet, i.e. 7-10 days.

Daily, single low-dose aspirin rapidly $(<30 \mathrm{~min})$ tips the TXA2/PGI2 balance in favor of PGI2, but has no impact on the production of PGI2 [26]. This explains the paradox of aspirin, which has a short half-life, but a prolonged effect on platelet aggregation. 
Ethanoic acid

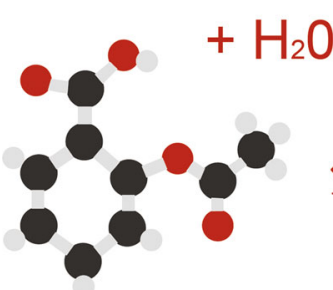

Aspirin
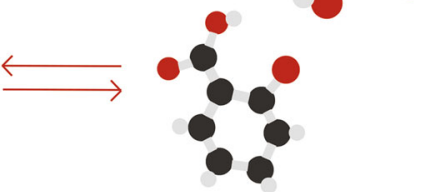

Salicylic acid

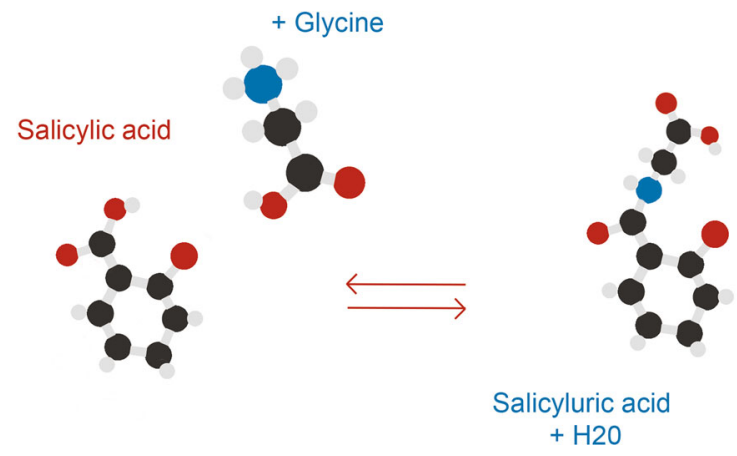

Fig. 2 Hydrolysis of aspirin and conjugation of salicylic acid

Sibai et al. reported that $60-80 \mathrm{mg}$ of aspirin a day reduced TXA 2 production in over $90 \%$ of pregnant women after some days of treatment [27]. Roberts et al. noted that

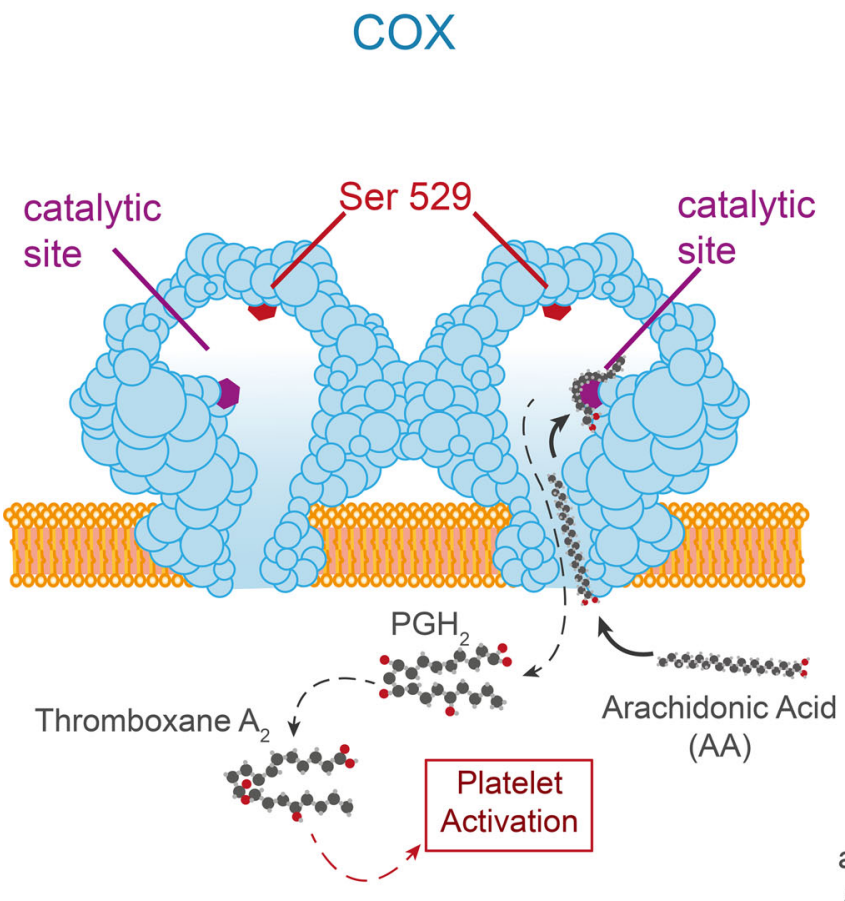

$50 \mathrm{mg}$ of aspirin a day reduced TXA2 production in over $95 \%$ of cases without altering prostacyclin production, whereas 100-300 mg of aspirin a day completely inhibited TXA2 production, and also inhibited prostacyclin [28, 29].

Aspirin also has other effects that seem to be independent of COX. It modifies hemostasis via decreased formation of thrombin [30] and increases fibrinolysis [31]. In the endothelium, aspirin modifies primary hemostasis via decreased expression of the tissue factor responsible for platelet adhesion [32]. Other studies have emphasized the biological prevention of tumor-necrosis factor (TNF)- $\alpha$ induced endothelial cell dysfunction by regulating the NF$\mathrm{kB} / \mathrm{eNOS}$ pathway [33], or the impact of aspirin on transcription factors such as STOX1 in preeclampsia-like syndromes in mice [34], or the effect of aspirin on hemeoxygenase-1, used as a diagnostic marker of oxidative stress in preeclampsia [35]. However, none of these pathways have been investigated in pregnant women.

\subsection{Chronobiology of Aspirin}

The efficacy of aspirin seems to be subject to a chronobiological effect, since a randomized trial in Spain showed a beneficial effect on diurnal blood pressure regulation and a reduction of obstetrical effects when aspirin was taken in the evening or at bedtime, compared with morning intake [hazard ratio $0.19,95 \%$ confidence interval (CI) $0.10-0.39$ ] [36]. This beneficial effect is principally dependent on circadian rhythms combined with the rest-activity cycle of

\section{COX after Aspirin}

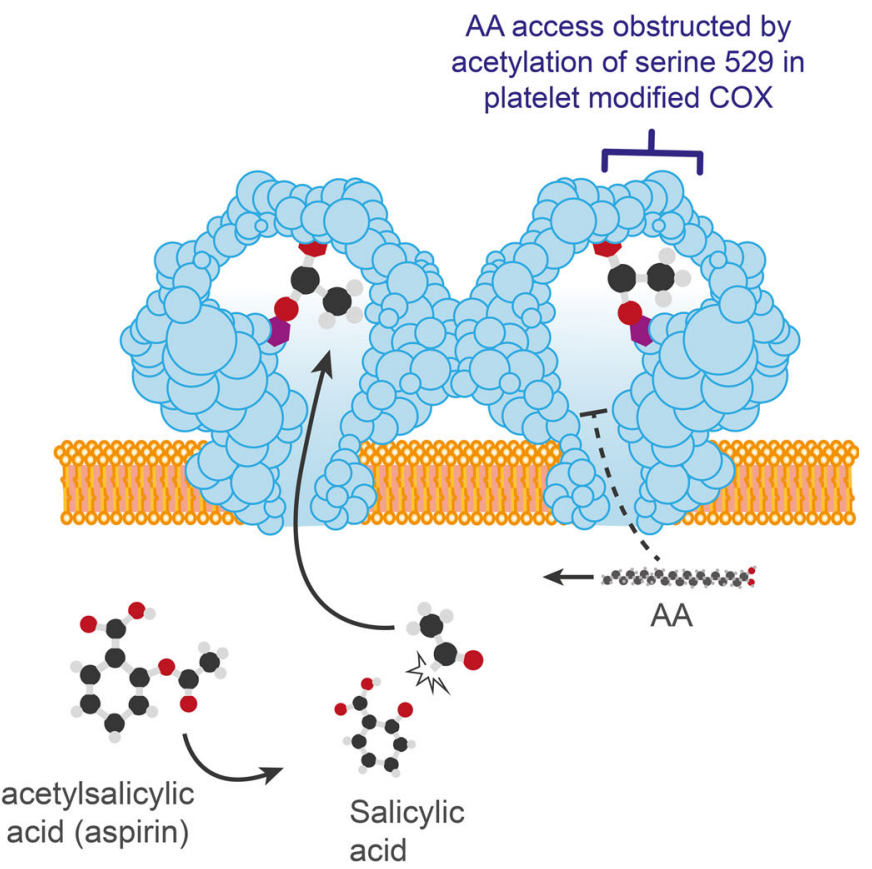

Fig. 3 Mode of action of aspirin. Ser serine, $C O X$ cyclooxygenase, $P G H 2$ prostaglandin $\mathrm{H} 2$, AA arachidonic acid 
patients. Aspirin seems to have a minor effect when taken in a single morning dose upon waking [36, 37].

In a randomized trial, Bonten et al. [37] found that COX-1-dependent platelet activity was significantly reduced upon awakening after low-dose aspirin taken the previous evening or on retiring. COX-1-independent platelet activity was not affected by aspirin intake or its timing [37]. Laboratory tests therefore confirm clinical data favoring evening or bedtime intake of low-dose aspirin.

\section{Prostaglandins and Pregnancy}

During normal pregnancy, the platelet TXA2 (platelet activator and vasoconstrictor) and endothelial prostacyclin (platelet inhibitor and vasodilator) balance favors prostacyclins. This equilibrium regulates platelet aggregation and peripheral vasoreactivity during pregnancy and maintains satisfactory uteroplacental blood flow [38].

Preeclampsia is a complication of pregnancy secondary to placental dysfunction. Initially, vascular uterine remodeling is altered, leading to decreased maternal blood supply to the placenta. Progressively, placental hypoxia and oxidative stress result in generalized dysfunction of the villous trophoblast. This placental dysfunction induces release into the maternal circulation of factors (free radicals, oxidized lipids, cytokines, sFlt-1) that cause generalized endothelial dysfunction, leading to clinical signs of the disease [39]. This endothelial dysfunction involves increased peroxidation of endothelial lipids associated with a decrease in antioxidant protection. The peroxidation of lipids activates COX and inhibits prostacyclin synthase, thus inducing rapid imbalance in the TXA2/prostacyclin (PGI2) ratio in favor of TXA2 [38]. TXA2 favors systemic vasoconstriction, which is little compensated in this context by the vasodilator effect of prostacyclins, levels of which drop sharply. In addition, epigenetic modifications of the promoter region of the thromboxane synthase gene (TBXAS1) during preeclampsia have been reported [40]. Analysis of the DNA of patients with preeclampsia has provided evidence of a decrease in methylation of the TBXAS1 promoter, leading to increased expression of thromboxane synthase [40]. In vitro, aspirin seems to improve defective trophoblast syncytialization by altering the production of specific cytokines, decreasing apoptosis, and altering cell aggregation and fusion [41]. Aspirin has no effect on trophoblastic invasion [42].

\section{Physiological Basis for Using Aspirin in Preeclampsia}

In preeclampsia, platelet TXA2 increases significantly, whereas prostacyclin drops sharply. This imbalance is present from 13 weeks of gestation in patients at high risk
[43]. TXA2/PGI2 imbalance can be reversed by 2 weeks of treatment with low-dose aspirin [44], which inhibits TXA2 secretion, and thus platelet aggregation [44], without altering secretion of endothelial prostacyclin (PGI2) [27], thereby favoring systemic vasodilatation.

More recent understanding of the influence of angiogenic factors on placental hemodynamics during pregnancy has led to assessment of the effect of aspirin on the secretion of these factors in the human placenta. In hypoxic conditions, aspirin inhibits the expression of sFlt-1 in human trophoblasts, and thus shows proangiogenic activity [45]. sFlt-1 is the soluble form of the VEGF receptor, which, in binding to circulating placenta growth factor (PlGF) and vascular endothelial growth factor (VEGF), behaves as a potent anti-angiogenic factor [46]. sFlt-1 is present at high levels in the circulation of patients with preeclampsia and is responsible for the angiogenic imbalance seen in the pathogenesis of preeclampsia [46, 47].

\subsection{History of the Use of Aspirin}

The early 1950s were marked by numerous studies showing that aspirin effectively prevents cardiovascular disease [48]. The first evidence of the obstetrical efficacy of aspirin was noted in 1985 by Beaufils et al. [49], in a randomized study of preventive treatment with aspirin in 102 patients at high risk of preeclampsia and/or intrauterine growth restriction [49]. The prevalence of preeclampsia was significantly reduced in the aspirin group compared with the untreated group $(0 / 48$ vs $6 / 45 p<0.05)$. These findings were welcomed by the scientific community, thus starting the golden age of the prevention of placental vascular disease by aspirin. Numerous randomized, double-blind trials subsequently assessed the efficacy of aspirin in these indications, notably in 1991, when the EPREDA trial showed a beneficial effect of aspirin in the secondary prevention of intrauterine growth restriction [50].

Between 1992 and 2001, prescriptions of aspirin soared and its indications in obstetrical practice multiplied. Numerous studies were published, using aspirin in patients considered as presenting risk factors, with gestational age at inclusion and dosages varying greatly between studies. The effect measured was clearly less than expected. In 1994, an attempt was made in the randomized CLASP trial to harmonize clinical practices and inclusions [51]. In a subsequent double-blind randomized trial, Caritis et al. found no benefit of the prescription of $60 \mathrm{mg}$ of aspirin from 13-26 weeks of gestation [52]. However, the indications used by Caritis et al. for the prescription of aspirin were very broad, and covered patients with diabetes before conception, chronic hypertension, multiple pregnancy, and gestational age $>20$ weeks at the start of aspirin treatment in over $50 \%$ of randomized patients [49]. 
The golden age of aspirin treatment for obstetrical indications in daily practice was thus questioned. It was not until 2001 that a meta-analysis of the efficacy of aspirin in the prevention of preeclampsia in high-risk patients [53] showed that low-dose aspirin (60-160 mg) reduced the risk of preeclampsia by $15 \%$ without changing the incidence of intrauterine growth restriction. The significant benefit of the prescription of low-dose aspirin was clearly below that suggested by early studies. Analysis of individual patient data was necessary to define the indications and a group of at-risk patients in the context of relevant medical indications [53]. A 2007 meta-analysis by Askie et al. [5], published by Duley et al. [54] in the Cochrane database, included over 37,000 patients in 59 trials assessing aspirin in primary and secondary prevention [54]. The analysis showed a significant but modest reduction of $10 \%$ [relative risk (RR) $0.90 ; 95 \%$ CI 0.84-0.97] in the risk of preeclampsia, a $10 \%$ decrease in the risk of delivery before 34 weeks of gestation (RR 0.90; 95\% CI 0.83-0.98), and a $10 \%$ reduction in the risk of unfavorable outcome (RR 0.90; 95\% CI 0.85-0.96) (Table 1). Askie et al. noted a more marked benefit when aspirin treatment started before 20 weeks of gestation (RR 0.87 ; 95\% CI $0.79-0.96$ ) and when the dosage was $\geq 75 \mathrm{mg} /$ day (RR 0.77 ; 95\% CI 0.61-0.97) [5]. So, the benefit demonstrated was lost when aspirin was introduced at $\geq 20$ weeks of gestation (RR 0.95 ; 95\% CI $0.85-1.06$ ) or at doses $\leq 75 \mathrm{mg}$ (RR 0.95; 95\% CI 0.92-0.99) (Table 2) [5].

Caron et al. in 2009 reported a dose-dependent effect of aspirin in pregnant women, thus confirming the association of an optimal dose for the measurement of a real clinical effect [29].

In view of the large number of patients and the availability of individual patient data in this meta-analysis, it was possible to analyze the efficacy of aspirin in subgroups. Aspirin did not reduce preeclampsia when prescribed because of certain risk factors, like nulliparity, chronic hypertension before pregnancy, diabetes before conception, age $>35$ years, twin pregnancies, and history of a small-for-gestational-age infant (Table 3). This meta-
Table 2 Effect of aspirin according to dosage and gestational age at the start of treatment, according to Askie et al. [5]

\begin{tabular}{lll}
\hline Condition & Relative risk & Confidence interval \\
\hline Gestational age $<20$ weeks & 0.87 & $0.79-0.96$ \\
Gestational age $\geq 20$ weeks & 0.95 & $0.85-1.06$ \\
Dose of aspirin $\leq 75 \mathrm{mg}$ & 0.95 & $0.92-0.99$ \\
Dose of aspirin $>75 \mathrm{mg}$ & 0.77 & $0.61-0.97$ \\
\hline
\end{tabular}

Table 3 Subgroup analysis: risk of preeclampsia Askie et al. [5]

\begin{tabular}{ll}
\hline Condition & RR $(95 \%$ CI $)$ \\
\hline Nulliparity & $0.90(0.76-1.08)$ \\
Multiparity with high risk factor & $0.89(0.81-0.99)$ \\
Hypertension before conception & $0.97(0.84-1.12)$ \\
Diabetes before conception & $0.76(0.56-1.04)$ \\
Nephropathy before conception & $0.63(0.38-1.06)$ \\
History of small-for-gestational-age infant & $1.05(0.86-1.28)$ \\
Age $>35$ years & $1.02(0.83-1.26)$ \\
Twin pregnancy & $0.85(0.61-1.18)$ \\
\hline
\end{tabular}

analysis is currently the most important because it is the only one performed with individual patient data.

Between 2007 and 2010, a multitude of contradictory studies and controversial conclusions prompted Bujold et al. to publish in 2010 a meta-analysis of 34 double-blind randomized trials measuring the effect of low-dose aspirin on the incidence of preeclampsia and intrauterine growth restriction [55]. Their findings were in accord with those of Askie et al. [5], but suggested a greater beneficial effect, especially when aspirin was started before 16 weeks of gestation (RR 0.47 ; 95\% CI 0.34-0.65) in high-risk patients. This effect was no longer significant when the treatment was started after 16 weeks of gestation (RR 0.81; 95\% CI 0.65-1.03). In the cohort of Askie et al., the patients who had early treatment mostly received it between 18 and 20 weeks of gestation, which explains the measurement bias referred to by Bujold et al. [55].

Table 1 Principal maternal and fetal events-Askie et al. [5]

\begin{tabular}{lll}
\hline Condition tested in favor of aspirin treatment & RR $(95 \% \mathrm{CI})$ & Number of patients needed to treat $(95 \% \mathrm{CI})$ \\
\hline Reduction in the risk of preeclampsia & $0.90(0.84-0.97)^{*}$ & $167(104-556)$ \\
Risk of delivery < 34 WG & $0.90(0.83-0.98)^{*}$ & $100(59-500)$ \\
Risk of unfavorable outcome & $0.90(0.85-0.96)^{*}$ & $67(44-167)$ \\
In utero fetal death & $0.91(0.81-1.03)$ & - \\
Small for gestational age & $0.90(0.81-1.01)$ & - \\
\hline
\end{tabular}

$W G$ Weeks of gestation, $C I$ confidence interval 
Considering that data are limited because of an inability to place women in the correct gestational age subgroup from relevant trials, Askie conducted an individual data analysis published in 2017. The aim of the study was to assess whether the treatment effects of antiplatelet agents on preeclampsia and its complications vary based on whether treatment is started before or after 16 weeks of gestation [56]. Their results showed no significant difference in the effects of antiplatelet therapy for women randomized before 16 weeks of gestation $(0.90 ; 95 \%$ CI $0.79-1.03)$ compared with those randomized at or after 16 weeks (0.90; 95\% CI 0.83-0.98). The effect of low-dose aspirin on preeclampsia and its complications was consistent, regardless of whether treatment is started before or after 16 weeks of gestation [56].

As for the risk of intrauterine growth restriction, Bujold et al. [55] found a risk reduction of $56 \%$ in patients at high risk when the treatment was started before 16 weeks of gestation (RR 0.44; 95\% CI 0.30-0.65). After 16 weeks, the risk reduction was not significant and virtually nil (RR 0.98; 95\% CI 0.87-1.10) [55]. The problem with metaanalysis without individual patient data is that subgroup analysis may be affected by several biases. Therefore, the most reliable meta-analysis remains the one published by Askie and colleagues.

The debate on the indications for aspirin in the prevention of preeclampsia was reopened in 2014 by the US Preventive Services Task Force (USPSTF) evidence review [57], which was designed to update the 2002 American Congress of Obstetricians and Gynecologists (ACOG) guidelines [58]. The efficacy of low-dose aspirin in the prevention of preeclampsia in high-risk patients, and in reduction of perinatal adverse events, was reviewed in order to update clinical practices and obstetrical prescriptions [57]. All trials included in the review exclusively considered the traditional definition of preeclampsia. The recommendations were above all based on the latest metaanalyses, which did not use individual patient data or allow specific study of the effect of aspirin as a function of the risk factors presented by patients (Table 4). However, the recommendations were formulated as a function of these different risk factors and the USPSTF recommended broad prescription of aspirin in patients with a high-risk factor for preeclampsia and in patients with at least two intermediate risk factors.

In the ensuing debate, some scientific and obstetrical experts noted that the USPSTF recommendations had moved away from the ACOG guidelines. Sibai et al. [60] highlighted that platelet inhibitors are advocated in patients with chronic hypertension, chronic nephropathy, or diabetes, a recommendation not made in previous publications or national recommendations [60]. In parallel, a 2015 socioeconomic study noted that wide-ranging prevention in line with USPSTF recommendations would be more costeffective in terms of reduced induction of prematurity and maternal morbidity [59]. The same study showed that the USPSTF recommendations would lead to the use of lowdose aspirin in $27.6 \%$ of pregnant women. These recommendations were followed by comments highlighting an unreasonable massive prescription of aspirin [60].

Current national guidelines on prevention of preeclampsia vary greatly: some are based on targeted indications in secondary prevention in cases of preeclampsia in a previous pregnancy (ACOG in the USA, Société Française de l'Hypertension Artérielle in France), others extend the indications as a function of the patients' risk factors (NICE, USPSTF, RANZCOG, SOGC). Table 5 summarizes the guidelines of various learned societies.

\subsection{Early Detection of Preeclampsia}

Timely detection of preeclampsia has been a major challenge in perinatal research for over 50 years. In 1947, Kraver et al. attempted to predict the onset of preeclampsia by the cold pressor test or Hines-Brown test, by studying maternal cardiovascular changes following immersion of the hand in ice-cold water [67]. The last 20 years have seen extensive research on clinical parameters, biophysical markers (Doppler indices), and various early biochemical markers that reflect impaired placentation [68-72]. Numerous tests were subsequently proposed for detection of preeclampsia in the first trimester, but were of
Table 4 Meta-analysis and effect of aspirin-after Werner et al. [59]

\begin{tabular}{llll}
\hline Authors, year & Number of trials included & Patients included & Preeclampsia - RR \\
\hline Askie et al. [5] & 36 & 34,288 & $0.9(0.84-0.97)$ \\
Duley et al. [54] & 39 & 37,560 & $0.83(0.77-0.89)$ \\
Bujold et al. [55] & 34 & 11,348 & $0.47(0.34-0.65)^{\mathrm{a}}$ \\
& & & $0.81(0.63-1.03)^{\mathrm{b}}$ \\
Henderson et al. [57, 62] & 23 & 12,184 & $0.76(0.62-0.95)$ \\
\hline
\end{tabular}

a Treatment introduced before 16 weeks of gestation

$\mathrm{b}$ Treatment introduced after 16 weeks of gestation 
Table 5 Prescription of low-dose aspirin according to learned societies

\begin{tabular}{llllllll}
\hline Country & $\begin{array}{l}\text { Personal history } \\
\text { of preeclampsia } \\
\text { or HELLP }\end{array}$ & $\begin{array}{l}\text { Autoimmune } \\
\text { disease } \\
\text { except for APS }\end{array}$ & APS & $\begin{array}{l}\text { Diabetes } \\
\text { (type 1 or 2) }\end{array}$ & $\begin{array}{l}\text { Renal } \\
\text { disease }\end{array}$ & $\begin{array}{l}\text { Chronic } \\
\text { hypertension }\end{array}$ & $\begin{array}{l}\text { Association } \\
\text { of moderate } \\
\text { risk factors }\end{array}$ \\
\hline France SFHTA CNGOF & Yes & \pm & Yes & No & No & No & No \\
USA USPSTF & Yes & Yes & Yes & Yes & Yes & Yes & Yes \\
USA ACOG & Yes & Yes & Yes & Yes & Yes & Yes & No \\
Canada SOGC & Yes & Yes & Yes & Yes & Yes & Yes & \pm \\
United Kingdom NICE & Yes & Yes & Yes & Yes & Yes & Yes & Yes \\
Australia New Zealand RANZCOG & Yes & Yes & Yes & Yes & Yes & Yes & Yes \\
\hline
\end{tabular}

APS Antiphospholipid syndrome, MP multiple pregnancy, SFHTA Société Française de l'Hypertension Artérielle, CNGOF Collège National des Gynécologues Obstétriciens Français [61], USPSTF US Preventive Services Task Force [62], ACOG American Congress of Obstetricians and Gynecologists [63], SOGC Society of Obstetricians and Gynaecologists of Canada [64], NICE National Institute for Health and Care Excellence [65], RANZCOG Royal Australian and New Zealand College of Obstetricians and Gynaecologists [66]

insufficient sensitivity and/or gave too many false-positive results for use in clinical practice. In 2007, Plasencia et al. confirmed that Doppler ultrasound before 16 weeks of gestation in the prediction of preeclampsia is of highly questionable utility. For a $10 \%$ false-positive rate, Doppler ultrasound had an insufficient detection rate of 41.1\% [73]. Moreover, the PREDO trial tested the effect of aspirin versus placebo in the prediction of preeclampsia in women with abnormal uterine artery Doppler flow velocimetry and no significant difference was found [74]. The first study that really opened the way to early detection of preeclampsia was published in 2009 by Poon et al. [75] of the Fetal Medicine Foundation (FMF), who proposed an algorithm for estimation of the risk of preeclampsia on the basis of maternal demographics, medical and obstetrical history, pulsatility index of the uterine arteries, mean blood pressure, and maternal serum levels of PlGF and pregnancy associated plasma protein A (PAPP-A) between 11 and 13 weeks of gestation. This test identified $91 \%$ cases of early and severe preeclampsia, with a $10 \%$ false-positive rate. In contrast, the test was poorly predictive of moderate preeclampsia and gestational hypertension. The Poon et al. study [75] was subject to potential bias, notably in the constitution of the control group of the nested case-control analysis, which could have led to overestimation of the efficiency of the algorithm.

Several other studies in large prospective cohorts subsequently focused on algorithms predictive of preeclampsia, but the results were disappointing [68-71]. Oliveira et al. [76, 77] in 2014 also discussed the limited external validity of these different tests, calling into question their application to the general population [76, 77]. The performance of the algorithms in the new population was indeed significantly poorer than in the original population. The sensitivity of the test proposed by Poon et al., initially given as $95 \%$, was $52 \%$ in the at-risk population tested by Oliveira et al. [76, 77]. The FMF algorithm is, however, the most studied and its performance in a population of 35,948 patients was in line with the findings of Poon et al. [75]. The estimated area under the curve of the test was 0.907 , with $89 \%$ sensitivity, and a $10 \%$ false-positive rate in the prediction of early preeclampsia [78].

\subsection{The ASPRE (Aspirin for Evidence-Based PREeclampsia Prevention) Trial}

To study the use of the FMF algorithm in clinical practice, the ASPRE trial was designed to propose aspirin as a treatment for primary prevention of preeclampsia in all patients considered to be at high risk following first-trimester combined screening. This multicenter, doubleblind, randomized, placebo-controlled trial evaluated the effect of prophylactic low-dose aspirin administered in the first trimester of pregnancy on the incidence of delivery with preeclampsia before 37 weeks of gestation in patients at high risk. The secondary objectives were to study the effects of aspirin on the incidence of early (delivery before 34 weeks of gestation) preeclampsia, the incidence of intrauterine growth restriction, fetal death, perinatal death, admission to neonatal intensive care, a composite measure of neonatal morbidity and mortality and placental abruption [79].

The risk cut-off used in this study was 1/100, which corresponds to about $10 \%$ of pregnant women. Patients considered at high risk were randomized to either a group given aspirin (150 mg per day, taken at bedtime) or a group given a placebo. Treatment was started in the first trimester (between 11 and 14 weeks of gestation) and continued to 36 weeks of gestation [79].

Testing was offered to 26,941 pregnant women, 2641 of whom were at high risk of preeclampsia and eligible for inclusion. Among the patients included, 1776 were randomized to aspirin or a placebo. The occurrence of preterm preeclampsia $(<37$ weeks) was significantly reduced by 
aspirin $(0.38 ; 95 \%$ CI $0.20-0.74 ; p=0.004)$. Preterm preeclampsia occurred in 13 of 798 participants $(1.6 \%)$ in the aspirin group, as compared with 35 of $822(4.3 \%)$ in the placebo group [79]. The effect of preeclampsia was more pronounced in nulliparous women (OR $0.27 ; 95 \%$ CI $0.11-0.65)$. There was no significant difference in the incidence of preeclampsia after 37 weeks (OR 0.95 . 95\% CI 0.57-1.57), small for gestational age with or without preeclampsia, placental abruption and spontaneous delivery with or without preeclampsia [79]. Moreover, there was no difference in the incidence of preterm preeclampsia in multiparous women with or without a history of preeclampsia (OR 0.5 ; 95\% CI $0.08-3.09$ and $0.79 ; 95 \%$ CI $0.22-2.88$, respectively). In this study, the dose of $150 \mathrm{mg}$ of aspirin per day was selected on the basis of previous evidence of a dose-dependent benefit [80]. Inclusion criteria contained a high risk ( $>1$ in 100) for preterm preeclampsia according to the screening algorithm. Interestingly, the incidence seemed to be significantly reduced only in women with an estimated risk for preterm preeclampsia ranging between 1 in 10.1 and 1 in 50 (OR 0.33; 95\% CI 0.13-0.84) [79]. Further studies considering this threshold ( $>1$ in 50) may refine the estimated high risk of preterm preeclampsia.

This study raises several questions. Is screening of preeclampsia based on the FMF algorithm more effective than current national guidelines (NICE, ACOG, etc.)? This question is the subject of an ongoing study in the UK (SPREE study) [81]. Meanwhile, the results from the ASPRE study suggest that a large number of patients need to be screened in order to avoid one case of preeclampsia [82]. In the ASPRE study, 25,797 patients were included and 630 developed preeclampsia. Aspirin was associated with a reduction of 21 cases of preterm preeclampsia. Therefore, to avoid one case of preterm preeclampsia, 1228 patients must be screened and nearly $10 \%$ of the population must be treated with aspirin. A medical economics study is also needed to evaluate the cost effectiveness of such prevention. We believe that more data are needed before implementing first-trimester screening of preeclampsia in real practice and before modification of national guidelines.

\section{Iatrogenic Fetal and Maternal Effects of Aspirin Treatment}

Aspirin is of unquestionable benefit in the prevention cardiovascular diseases [83], and its side effects and iatrogenesis seem minor, thus enabling routine prescription given its favorable benefit-risk ratio. However, gastrointestinal discomfort seems constant [84-86] and some studies report rare but serious side effects, notably hemorrhagic [87-89]. Its widespread use has led to more frequent administration of aspirin during pregnancy, and to iatrogenic risk for mother and child. Aspirin crosses the placental barrier and alters TXA2/PGI2 balance and platelet aggregation in the fetus [90]. After perfusion into the placental cotyledon, aspirin is transferred into the fetal-placental circulation during the first $5 \mathrm{~min}$ [91]. Laboratory tests on cord blood in pregnant women taking low-dose aspirin (100 mg/day) have revealed no salicylate or other metabolites, but there is a sharp drop in platelet TXA2, which returns to normal 2-3 days after the discontinuation of post-partum treatment [90]. Aspirin thus has a hematological effect on the fetus via the uteroplacental circulation. With early and prolonged use of aspirin doses $>180 \mathrm{mg} /$ day, Hertz et al. [92] reported sporadic cases of intracranial hemorrhage in premature infants, in low-weight children, and when there is early closure of the arterial canal [92]. The principal studies of fetal and maternal iatrogenesis are reassuring, and low doses of aspirin administered during the first trimester do not seem to constitute a teratogenic risk [93-96]. However, aspirin treatment leads to a decrease in fetal platelet aggregation and so to a theoretical risk of in utero cerebral hemorrhage. This risk is low, but cases of such adverse effects may increase in number with widespread prescription of aspirin in pregnant women $[92,97]$. As aspirin treatment should be discontinued around 36 weeks of gestation, the risk particularly concerns women who give birth before this term. Aspirin could therefore augment the risk of bleeding associated with prematurity. Teratogenicity associated with aspirin concerns only patients exposed to doses of between 650 and $2600 \mathrm{mg} /$ day, with variable clinical expression including cardiopathies and limb anomalies. Such events are not seen at lower doses [92]. Finally, low-dose aspirin seems not to influence birthweight or the duration of pregnancy [92].

It is reassuring that prophylactic use of aspirin has no negative effect on perinatal mortality [48]. Numerous studies show that low-dose aspirin during pregnancy has a positive impact on clinical or laboratory findings, or both.

Despite the gastrointestinal symptoms reported in $10 \%$ of patients taking aspirin, there is no increase in the risk of bleeding or of placental abruption [55, 98]. Likewise, the literature indicates no significant association between lowdose aspirin treatment and premature closure of the arterial canal or neonatal bleeding [99-101]. However, the power of these studies was not enough to show the potential side effects associated with routine and extensive prescription. Apart from pregnancy, large studies were needed to show the risks, notably hemorrhagic, associated with low-dose aspirin. The broadening of the indications for aspirin in pregnant women has led to the exposure to these potential 
side effects of more and more women and fetuses. As an example, a test involving prescription of aspirin to $10 \%$ of pregnant women would lead each year to the treatment of 400,000 pregnant women in the USA, 80,000 in France, and $1,800,000$ in China. The USPSTF recommendations would mean that three times more patients would be treated every year. It is therefore essential to put in place screening tools that limit the needless exposure of pregnant women to aspirin.

\section{Conclusion}

It is now clear that low doses of aspirin are effective in secondary prevention of preeclampsia in high-risk patients, mainly those with a history of preeclampsia. Aspirin inhibits thromboxane A2 production by platelets and so increases the prostacyclin/TXA2 ratio and reduces platelet aggregation. It also decreases production of the tissue factor thrombin. Indications for aspirin in primary prevention are a matter of debate, but recent publications suggest a strategy based on first-trimester screening of preeclampsia (with clinical parameters, biomarkers and uterine Doppler measurements) and aspirin administration to high-risk patients. The usefulness of this strategy is still under evaluation and more data are needed before its implementation in real practice. Aspirin should be administered once a day in the evening at low doses ranging from 80 to $150 \mathrm{mg}$. There is good evidence showing that the efficacy of aspirin grows as the dose increases. However, aspirin crosses the placental barrier and inhibits fetal platelet aggregation. Although low-dose aspirin has a good maternal and fetal safety profile, the number of patients exposed to doses over $100 \mathrm{mg}$ is low and the safety of a prevention strategy based on $150 \mathrm{mg}$ of aspirin per day has to be confirmed.

\section{Compliance with Ethical Standards}

Conflict of interest VT is a consultant for Roche Diagnostics and principal investigator of the PRECOG study, a study partly funded by Roche Diagnostics. AA, EL, FG, MD-D and PG declare that they have no conflict of interest.

Funding Payment for open access is provided by the Pierre Budin Association, a French association promoting research and teaching in perinatology.

Open Access This article is distributed under the terms of the Creative Commons Attribution-NonCommercial 4.0 International License (http://creativecommons.org/licenses/by-nc/4.0/), which permits any noncommercial use, distribution, and reproduction in any medium, provided you give appropriate credit to the original author(s) and the source, provide a link to the Creative Commons license, and indicate if changes were made.

\section{References}

1. Gaspoz J-M, Coxson PG, Goldman PA, et al. Cost effectiveness of aspirin, clopidogrel, or both for secondary prevention of coronary heart disease. N Engl J Med. 2002;346:1800-6. doi:10. 1056/NEJM200206063462309.

2. Cadavid AP. Aspirin: the mechanism of action revisited in the context of pregnancy complications. Front Immunol. 2017;8:261. doi:10.3389/fimmu.2017.00261.

3. Kattah AG, Garovic VD. The management of hypertension in pregnancy. Adv Chronic Kidney Dis. 2013;20:229-39. doi:10. 1053/j.ackd.2013.01.014.

4. Bergel E, Carroli G, Althabe F. Ambulatory versus conventional methods for monitoring blood pressure during pregnancy. Cochrane Database Syst Rev 2002:CD001231. doi:10.1002/ 14651858.CD001231.

5. Askie LM, Duley L, Henderson-Smart DJ, Stewart LA. Antiplatelet agents for prevention of pre-eclampsia: a meta-analysis of individual patient data. The Lancet. 2007;369:1791-8. doi:10. 1016/S0140-6736(07)60712-0.

6. Woelkers D, Barton J, von Dadelszen P, Sibai B. The revised 2013 ACOG definitions of hypertensive disorders of pregnancy significantly increase the diagnostic prevalence of preeclampsia. Pregnancy Hypertens Int $\mathbf{J}$ Womens Cardiovasc Health. 2015;5:38. doi:10.1016/j.preghy.2014.10.075.

7. Duley L. The global impact of pre-eclampsia and eclampsia. Semin Perinatol. 2009;33:130-7. doi:10.1053/j.semperi.2009. 02.010 .

8. von Dadelszen P, Magee LA. Pre-eclampsia: an update. Curr Hypertens Rep. 2014;16:1-14. doi:10.1007/s11906-014-0454-8.

9. Say L, Chou D, Gemmill A, Tunçalp Ö, Moller A-B, Daniels J, et al. Global causes of maternal death: a WHO systematic analysis. Lancet Glob Health. 2014;2:e323-33. doi:10.1016/ S2214-109X(14)70227-X.

10. Lafont O. From the willow to aspirin. Rev Hist Pharm. 2007;55:209-16.

11. Botting RM. Vane's discovery of the mechanism of action of aspirin changed our understanding of its clinical pharmacology. Pharmacol Rep PR. 2010;62:518-25.

12. West GB. Aspirin and the prostaglandins. Chem Drug. 1972;198:196-7.

13. Smith WL. The eicosanoids and their biochemical mechanisms of action. Biochem J. 1989;259:315.

14. Mitchell JA, Ahmetaj-Shala B, Kirkby NS, Wright WR, Mackenzie LS, Reed DM, et al. Role of prostacyclin in pulmonary hypertension. Glob Cardiol Sci Pract. 2014;2014:382. doi: $10.5339 / \mathrm{gcsp} .2014 .53$.

15. Maclouf J, Bellucci S. Role of prostaglandins and thromboxanes in cardiovascular physiopathology. Presse Medicale Paris Fr. 1983;1985(14):1603-6.

16. Bowen RS, Zhang Y, Gu Y, Lewis DF, Wang Y. Increased phospholipase A2 and thromboxane but not prostacyclin production by placental trophoblast cells from normal and preeclamptic pregnancies cultured under hypoxia condition. Placenta. 2005;26:402-9. doi:10.1016/j.placenta.2004.07.007.

17. Mitchell JA, Akarasereenont P, Thiemermann C, Flower RJ, Vane JR. Selectivity of nonsteroidal antiinflammatory drugs as inhibitors of constitutive and inducible cyclooxygenase. Proc Natl Acad Sci USA. 1993;90:11693-7.

18. Lu Y, Wahl LM. Oxidative stress augments the production of matrix metalloproteinase-1, cyclooxygenase-2, and prostaglandin E2 through enhancement of NF-kappa B activity in lipopolysaccharide-activated human primary monocytes. J Immunol Baltim Md. 1950;2005(175):5423-9. 
19. Chiang N, Serhan CN. Aspirin triggers formation of anti-inflammatory mediators: new mechanism for an old drug. Discov Med. 2004;4:470-5.

20. Takahashi Y. Molecular structure and regulation of cyclooxygenase. Nihon Rinsho Jpn J Clin Med. 1992;50:259-63.

21. Trnavský K, Zachar M. Correlation of serum aspirin esterase activity and half-life of salicylic acid. Agents Actions. 1975;5:549-52.

22. Bojić M, Sedgeman CA, Nagy LD, Guengerich FP. Aromatic hydroxylation of salicylic acid and aspirin by human cytochromes P450. Eur J Pharm Sci Off J Eur Fed Pharm Sci. 2015;73:49-56. doi:10.1016/j.ejps.2015.03.015.

23. Patrono C, Ciabattoni G, Patrignani P, Pugliese F, Filabozzi P, Catella F, et al. Clinical pharmacology of platelet cyclooxygenase inhibition. Circulation. 1985;72:1177-84.

24. Patrono C. Aspirin and human platelets: from clinical trials to acetylation of cyclooxygenase and back. Trends Pharmacol Sci. 1989;10:453-8. doi:10.1016/S0165-6147(89)80010-0.

25. Das UN. COX-2 inhibitors and metabolism of essential fatty acids. Med Sci Monit Int Med J Exp Clin Res. 2005;11:RA233-7.

26. Patrick J, Dillaha L, Armas D, Sessa WC. A randomized trial to assess the pharmacodynamics and pharmacokinetics of a single dose of an extended-release aspirin formulation. Postgrad Med. 2015;127:573-80. doi:10.1080/00325481.2015.1050341.

27. Sibai BM, Mirro R, Chesney CM, Leffler C. Low-dose aspirin in pregnancy. Obstet Gynecol. 1989;74:551-7.

28. Roberts MS, Joyce RM, McLeod LJ, Vial JH, Seville PR. Slowrelease aspirin and prostaglandin inhibition. Lancet Lond Engl. 1986;1:1153-4.

29. Caron N, Rivard G-E, Michon N, Morin F, Pilon D, Moutquin $\mathrm{J}-\mathrm{M}$, et al. Low-dose ASA response using the PFA-100 in women with high-risk pregnancy. J Obstet Gynaecol Can JOGC J Obstet Gynecol Can JOGC. 2009;31:1022-7.

30. Wegert W, Graff J, Kaiser D, Breddin HK, Klinkhardt U, Harder $\mathrm{S}$. Effects of antiplatelet agents on platelet-induced thrombin generation. Int J Clin Pharmacol Ther. 2002;40:135-41.

31. Basinski A, Naylor CD. Aspirin and fibrinolysis. Lancet Lond Engl. 1988;2:1188-9.

32. Chen Y-H, Lin S-J, Chen Y-L, Liu P-L, Chen J-W. Anti-inflammatory effects of different drugs/agents with antioxidant property on endothelial expression of adhesion molecules. Cardiovasc Hematol Disord Drug Targets. 2006;6:279-304.

33. Kim J, Lee K-S, Kim J-H, Lee D-K, Park M, Choi S, et al. Aspirin prevents TNF- $\alpha$-induced endothelial cell dysfunction by regulating the NF- $\kappa B$-dependent miR-155/eNOS pathway: role of a miR-155/eNOS axis in preeclampsia. Free Radic Biol Med. 2017;104:185-98. doi:10.1016/j.freeradbiomed.2017.01.010.

34. Doridot L, Passet B, Méhats C, Rigourd V, Barbaux S, Ducat A, et al. Preeclampsia-like symptoms induced in mice by fetoplacental expression of STOX1 are reversed by aspirin treatment. Hypertens Dallas Tex. 1979;2013(61):662-8. doi:10.1161/ HYPERTENSIONAHA.111.202994.

35. Erdemli HK, Yıldırımlar P, Alper TY, Kocabaş R, Salis O, Bedir A. Increased serum heme oxygenase-1 levels as a diagnostic marker of oxidative stress in preeclampsia. Hypertens Pregnancy. 2014;33:488-97. doi:10.3109/10641955.2014.946613.

36. Ayala DE, Ucieda R, Hermida RC. Chronotherapy with lowdose aspirin for prevention of complications in pregnancy. Chronobiol Int. 2013;30:260-79. doi:10.3109/07420528.2012. 717455.

37. Bonten TN, Saris A, van Oostrom MJ, Snoep JD, Rosendaal FR, Zwaginga $J$, et al. Effect of aspirin intake at bedtime versus on awakening on circadian rhythm of platelet reactivity. A randomised cross-over trial. Thromb Haemost. 2014;112:1209-18. doi:10.1160/TH14-05-0453.
38. Walsh SW. Eicosanoids in preeclampsia. Prostaglandins Leukot Essent Fatty Acids. 2004;70:223-32.

39. Lecarpentier E, Haddad B, Goffinet F, Tsatsaris V. Moyens thérapeutiques de la prise en charge de la pré-éclampsie. Presse Médicale. 2016;. doi:10.1016/j.lpm.2016.04.017.

40. Mousa AA, Strauss JF, Walsh SW. Reduced methylation of the thromboxane synthase gene is correlated with its increased vascular expression in preeclampsia. Hypertension. 2012;59:1249-55. doi:10.1161/hypertensionaha.111.188730.

41. Panagodage S, Yong HE, Da Silva Costa F, Borg AJ, Kalionis B, Brennecke SP, Murthi P. Low-dose acetylsalicylic acid treatment modulates the production of cytokines and improves trophoblast function in an in vitro model of early-onset preeclampsia. Am J Pathol. 2016;186(12):3217-24.

42. Scazzocchio E, Oros D, Diaz D, Ramirez JC, Ricart M, Meler E, et al. Impact of aspirin on trophoblastic invasion in women with abnormal uterine artery Doppler at 11-14 weeks: a randomized controlled study. Ultrasound Obstet Gynecol Off J Int Soc Ultrasound Obstet Gynecol. 2017;49:435-41. doi:10.1002/uog.17351.

43. Walsh SW. Low-dose aspirin: treatment for the imbalance of increased thromboxane and decreased prostacyclin in preeclampsia. Am J Perinatol. 1989;6:124-32. doi:10.1055/s2007-999562.

44. Perneby C, Vahter M, Åkesson A, Bremme K, Hjemdahl P. Thromboxane metabolite excretion during pregnancy - influence of preeclampsia and aspirin treatment. Thromb Res. 2011;127:605-6. doi:10.1016/j.thromres.2011.01.005.

45. Li C, Raikwar NS, Santillan MK, Santillan DA, Thomas CP. Aspirin inhibits expression of sFLT1 from human cytotrophoblasts induced by hypoxia, via cyclo-oxygenase 1 . Placenta. 2015;36:446-53. doi:10.1016/j.placenta.2015.01.004.

46. Vieillefosse S, Guibourdenche J, Atallah A, Haddad B, Fournier T, Tsatsaris V, et al. Predictive and prognostic factors of preeclampsia: interest of PIGF and sFLT-1. J Gynecol Obstet Biol Reprod (Paris). 2016;45:999-1008. doi:10.1016/j.jgyn.2016.02.006.

47. Tsatsaris V, Goffin F, Munaut C, Brichant J-F, Pignon M-R, Noel A, et al. Overexpression of the soluble vascular endothelial growth factor receptor in preeclamptic patients: pathophysiological consequences. J Clin Endocrinol Metab. 2003;88:5555-63. doi:10.1210/jc.2003-030528.

48. Craven LL. Prevention of coronary and cerebral thrombosis. Miss Val Med J Quincy Ill. 1956;78:213-5.

49. Beaufils M, Donsimoni R, Uzan S, Colau JC. Prevention of preeclampsia by early antiplatelet therapy. The Lancet. 1985;325:840-2. doi:10.1016/S0140-6736(85)92207-X.

50. Uzan S, Beaufils M, Breart G, Uzan S, Bazin B, Capitant C, et al. Originally published as Volume 1, Issue 8755Prevention of fetal growth retardation with low-dose aspirin: findings of the EPREDA trial. The Lancet. 1991;337:1427-31. doi:10.1016/ 0140-6736(91)93124-R.

51. Anonymous. CLASP: a randomised trial of low-dose aspirin for the prevention and treatment of pre-eclampsia among 9364 pregnant women. CLASP (Collaborative Low-dose Aspirin Study in Pregnancy) Collaborative Group. Lancet. 1994;343(8898):619-29.

52. Caritis S, Sibai B, Hauth J, Lindheimer MD, Klebanoff M, Thom E, et al. Low-dose aspirin to prevent preeclampsia in women at high risk. N Engl J Med. 1998;338:701-5. doi:10. 1056/NEJM199803123381101.

53. Duley L, Henderson-Smart D, Knight M, King J. Antiplatelet drugs for prevention of pre-eclampsia and its consequences: systematic review. BMJ. 2001;322:329-33.

54. Duley L, Henderson-Smart DJ, Meher S, King JF. Antiplatelet agents for preventing pre-eclampsia and its complications. In: The Cochrane Collaboration (ed). Cochrane Database Syst. Rev. Wiley, Chichester; 2007. 
55. Bujold E, Roberge S, Lacasse Y, Bureau M, Audibert F, Marcoux S, et al. Prevention of preeclampsia and intrauterine growth restriction with aspirin started in early pregnancy: a meta-analysis. Obstet Gynecol. 2010;116:402-14. doi:10.1097/ AOG.0b013e3181e9322a.

56. Meher S, Duley L, Hunter K, Askie L. Antiplatelet therapy before or after 16 weeks' gestation for preventing preeclampsia: an individual participant data meta-analysis. Am J Obstet Gynecol. 2017;216(121-128):e2. doi:10.1016/j.ajog.2016.10. 016.

57. Henderson JT, Whitlock EP, O'Conner E, Senger CA, Thompson JH, Rowland MG. Low-dose aspirin for the prevention of morbidity and mortality from preeclampsia: a systematic evidence review for the U.S. Preventive services task force. Rockville (MD): Agency for Healthcare Research and Quality (US); 2014.

58. ACOG Committee on Practice Bulletins-Obstetrics. ACOG practice bulletin. Diagnosis and management of preeclampsia and eclampsia. Number 33, January 2002. Obstet Gynecol. 2002;99:159-67.

59. Werner EF, Hauspurg AK, Rouse DJ. A cost-benefit analysis of low-dose aspirin prophylaxis for the prevention of preeclampsia in the United States. Obstet Gynecol. 2015;126:1242-50.

60. Sibai BM. Therapy: low-dose aspirin to reduce the risk of preeclampsia? Nat Rev Endocrinol. 2015;11:6-8. doi:10.1038/ nrendo.2014.199.

61. MOUNIER-VEHIER C. Consensus d'Experts de la Société Française d'Hypertension Artérielle 2015. http://www.sfhta.eu/wpcontent/uploads/2015/11/Recommandations_HTA_et_grossesse_ dec_2015202.pdf. Accessed 19 June 2016.

62. Henderson JT, Whitlock EP, O'Connor E, Senger CA, Thompson JH, Rowland MG. Low-dose aspirin for prevention of morbidity and mortality from preeclampsia: a systematic evidence review for the U.S. Preventive Services Task Force. Ann Intern Med. 2014;160:695-703. doi:10.7326/M13-2844.

63. Practice Advisory on Low-Dose Aspirin and Prevention of Preeclampsia: Updated Recommendations-ACOG n.d. http:// www.acog.org/About-ACOG/News-Room/Practice-Advisories/ Practice-Advisory-Low-Dose-Aspirin-and-Prevention-of-Preeclampsia-Updated-Recommendations. Accessed 20 Apr 2017.

64. Diagnosis, evaluation, and management of the hypertensive disorders of pregnancy: executive summary n.d. https://sogc.org/ wp-content/uploads/2014/05/gui307CPG1405Erev.pdf.

65. Hypertension in pregnancy: diagnosis and management I Guidance and guidelines I NICE n.d. https://www.nice.org.uk/ guidance/CG107. Accessed 20 Apr 2017.

66. Guidance regarding the use of low-dose aspirin in the prevention of pre-eclampsia in high-risk women. n.d. https://www.midwife. org.nz/.

67. Krieger VI, Weiden S. The value of the cold pressor test in the prediction of hypertension and toxaemia in pregnancy. Med $\mathrm{J}$ Aust. 1947;1:417-23.

68. Parra-Cordero M, Turan OM, Kaur A, Pearson JD, Nicolaides KH. Maternal serum soluble adhesion molecule levels at $11+0-13+6$ weeks and subsequent development of preeclampsia. J Matern-Fetal Neonatal Med Off J Eur Assoc Perinat Med Fed Asia Ocean Perinat Soc Int Soc Perinat Obstet. 2007;20:793-6. doi:10.1080/14767050701500349.

69. Caradeux J, Serra R, Nien J-K, Pérez-Sepulveda A, Schepeler M, Guerra F, et al. First trimester prediction of early onset preeclampsia using demographic, clinical, and sonographic data: a cohort study. Prenat Diagn. 2013;33:732-6. doi:10.1002/pd. 4113.

70. Scazzocchio E, Figueras F, Crispi F, Meler E, Masoller N, Mula $\mathrm{R}$, et al. Performance of a first-trimester screening of preeclampsia in a routine care low-risk setting. Am J Obstet Gynecol. 2013;208:203.e1-10. doi:10.1016/j.ajog.2012.12.016.

71. Odibo AO, Patel KR, Spitalnik A, Odibo L, Huettner P. Placental pathology, first-trimester biomarkers and adverse pregnancy outcomes. J Perinatol Off $\mathrm{J}$ Calif Perinat Assoc. 2014;34:186-91. doi:10.1038/jp.2013.176.

72. Parra-Cordero M, Rodrigo R, Barja P, Bosco C, Rencoret G, Sepúlveda-Martinez A, et al. Prediction of early and late preeclampsia from maternal characteristics, uterine artery Doppler and markers of vasculogenesis during first trimester of pregnancy. Ultrasound Obstet Gynecol Off J Int Soc Ultrasound Obstet Gynecol. 2013;41:538-44. doi:10.1002/uog.12264.

73. Plasencia W, Maiz N, Bonino S, Kaihura C, Nicolaides KH. Uterine artery Doppler at $11+0$ to $13+6$ weeks in the prediction of pre-eclampsia. Ultrasound Obstet Gynecol. 2007;30:742-9. doi:10.1002/uog.5157.

74. Villa PM, Kajantie E, Räikkönen K, Pesonen A-K, Hämäläinen $\mathrm{E}$, Vainio M, et al. Aspirin in the prevention of pre-eclampsia in high-risk women: a randomised placebo-controlled PREDO Trial and a meta-analysis of randomised trials. BJOG Int $\mathbf{J}$ Obstet Gynaecol. 2013;120:64-74. doi:10.1111/j.1471-0528. 2012.03493.x.

75. Poon LCY, Kametas NA, Maiz N, Akolekar R, Nicolaides KH. First-trimester prediction of hypertensive disorders in pregnancy. Hypertens Dallas Tex. 1979;2009(53):812-8. doi:10. 1161/HYPERTENSIONAHA.108.127977.

76. Oliveira N, Doyle LE, Atlas RO, Jenkins CB, Blitzer MG, Baschat AA. External validity of first-trimester algorithms in the prediction of pre-eclampsia disease severity. Ultrasound Obstet Gynecol Off J Int Soc Ultrasound Obstet Gynecol. 2014;44:286-92. doi:10.1002/uog.13433.

77. Oliveira N, Magder LS, Blitzer MG, Baschat AA. First-trimester prediction of pre-eclampsia: external validity of algorithms in a prospectively enrolled cohort. Ultrasound Obstet Gynecol Off J Int Soc Ultrasound Obstet Gynecol. 2014;44:279-85. doi:10. 1002/uog.13435.

78. O'Gorman N, Wright D, Syngelaki A, Akolekar R, Wright A, Poon LC, et al. Competing risks model in screening for preeclampsia by maternal factors and biomarkers at 11-13 weeks gestation. Am J Obstet Gynecol. 2016;214:103.e112. doi:10.1016/j.ajog.2015.08.034.

79. Rolnik D, Wright D, Poon L, O'Gorman N, Syngelaki A, de Paco Matallana C, et al. Aspirin versus placebo in pregnancies at high risk for preterm preeclampsia. N Engl J Med. 2017; . doi:10. 1056/NEJMoa1704559.

80. Roberge S, Nicolaides KH, Desmers S, Hyett J, Chaillet N, Bujold E. The role of aspirin dose on the prevention of preeclampsia and fetal growth restriction: systematic review and meta-analysis. Am J Obstet Gynecol. 2017;216(110-120):e6.

81. Tan M, Koutoulas L, Wright D, Nicolaides KH, Poon L. A study protocol for the prospective validation study: screening programme for pre-eclampsia (SPREE). Ultrasound Obstet Gynecol. 2017; doi:10.1002/uog.17467.

82. Rolnik DL, Wright D, Poon LCY, Syngelaki A, O'Gorman N, de Paco Matallana C, et al. ASPRE trial: performance of screening for preterm pre-eclampsia. Ultrasound Obstet Gynecol Off J Int Soc Ultrasound Obstet Gynecol. 2017;. doi:10.1002/ uog. 18816.

83. Mahmoud AN, Elgendy AY, Rambarat C, Mahtta D, Elgendy IY, Bavry AA. Efficacy and safety of aspirin in patients with peripheral vascular disease: an updated systematic review and meta-analysis of randomized controlled trials. PLoS One. 2017;12:e0175283. doi:10.1371/journal.pone.0175283.

84. Chen W-C, Lin K-H, Huang Y-T, Tsai T-J, Sun W-C, Chuah $\mathrm{S}-\mathrm{K}$, et al. The risk of lower gastrointestinal bleeding in low- 
dose aspirin users. Aliment Pharmacol Ther. 2017;. doi:10.1111/ apt.14079.

85. Benito-Garcia E, Michaud K, Wolfe F. The effect of low-dose aspirin on the decreased risk of development of dyspepsia and gastrointestinal ulcers associated to cyclooxygenase- 2 selective inhibitors. J Rheumatol. 2007;34:1765-9.

86. Belcon MC, Rooney PJ, Tugwell P. Aspirin and gastrointestinal haemorrhage: a methodologic assessment. J Chronic Dis. 1985;38:101-11.

87. Stevenson DD, White AA, Simon RA. Aspirin as a cause of pancreatitis in patients with aspirin-exacerbated respiratory disease. J Allergy Clin Immunol. 2012;129:1687-8. doi:10. 1016/j.jaci.2012.04.016.

88. Kennedy JL, Stoner AN, Borish L. Aspirin-exacerbated respiratory disease: prevalence, diagnosis, treatment, and considerations for the future. Am J Rhinol Allergy. 2016;30:407-13. doi:10.2500/ajra.2016.30.4370.

89. Lei H, Gao Q, Liu S-R, Xu J. The benefit and safety of aspirin for primary prevention of ischemic stroke: a meta-analysis of randomized trials. Front Pharmacol. 2016;7:440. doi:10.3389/ fphar.2016.00440.

90. Leonhardt A, Bernert S, Watzer B, Schmitz-Ziegler G, Seyberth HW. Low-dose aspirin in pregnancy: maternal and neonatal aspirin concentrations and neonatal prostanoid formation. Pediatrics. 2003;111:e77-81. doi:10.1542/peds.111.1.e77.

91. Jacobson RL, Brewer A, Eis A, Siddiqi TA, Myatt L. Transfer of aspirin across the perfused human placental cotyledon. Am J Obstet Gynecol. 1991;165:939-44.

92. Hertz-Picciotto I, Hopenhayn-Rich C, Golub M, Hooper K. The risks and benefits of taking aspirin during pregnancy. Epidemiol Rev. 1990;12:108-48.

93. Slone D, Siskind V, Heinonen OP, Monson RR, Kaufman DW, Shapiro S. Aspirin and congenital malformations. Lancet Lond Engl. 1976;1:1373-5.
94. Klebanoff MA, Berendes HW. Aspirin exposure during the first 20 weeks of gestation and IQ at four years of age. Teratology. 1988;37:249-55. doi:10.1002/tera.1420370310.

95. Werler MM, Mitchell AA, Shapiro S. The relation of aspirin use during the first trimester of pregnancy to congenital cardiac defects. N Engl J Med. 1989;321:1639-42. doi:10.1056/ NEJM198912143212404.

96. Nørgård B, Puhó E, Czeizel AE, Skriver MV, Sørensen HT. Aspirin use during early pregnancy and the risk of congenital abnormalities: a population-based case-control study. Am J Obstet Gynecol. 2005;192:922-3. doi:10.1016/j.ajog.2004.10.598.

97. Sasidharan CK, Kutty PM, Ajithkumar, Sajith N. Fetal intracranial hemorrhage due to antenatal low dose aspirin intake. Indian J Pediatr. 2001;68(11):1071-2.

98. Rotchell YE, Cruickshank JK, Gay MP, Griffiths J, Stewart A, Farrell B, et al. Barbados Low Dose Aspirin Study in Pregnancy (BLASP): a randomised trial for the prevention of pre-eclampsia and its complications. Br J Obstet Gynaecol. 1998;105:286-92.

99. Di Sessa TG, Moretti ML, Khoury A, Pulliam DA, Arheart KL, Sibai BM. Cardiac function in fetuses and newborns exposed to low-dose aspirin during pregnancy. Am J Obstet Gynecol. 1994;171:892-900.

100. Schiessl B, Schneider KT, Zimmermann A, Kainer F, Friese K, Oberhoffer R. Prenatal constriction of the fetal ductus arteriosus-related to maternal pain medication? Z Geburtshilfe Neonatol. 2005;209:65-8. doi:10.1055/s-2005-864116.

101. Wyatt-Ashmead J. Antenatal closure of the ductus arteriosus and hydrops fetalis. Pediatr Dev Pathol Off J Soc Pediatr Pathol Paediatr Pathol Soc. 2011;14:469-74. doi:10.2350/07-11-0368.1. 